\title{
Identification of genes differentially expressed during prenatal development of skeletal muscle in two pig breeds differing in muscularity
}

\author{
Eduard Muráni ${ }^{1}$, Mária Murániová2 ${ }^{2}$ Siriluck Ponsuksili ${ }^{3}$, Karl Schellander ${ }^{2}$ \\ and Klaus Wimmers*1
}

Address: ${ }^{1}$ Research Institute for the Biology of Farm Animals (FBN), Research Unit Molecular Biology, Wilhelm-Stahl-Allee 2, 18196 Dummerstorf, Germany, ${ }^{2}$ Institute of Animal Science, Animal Breeding and Husbandry Group, University of Bonn, Endenicher Allee 15, 53115 Bonn, Germany and ${ }^{3}$ Research Institute for the Biology of Farm Animals (FBN), Research Group Functional Genomics, 18196 Dummerstorf, Germany

Email: Eduard Muráni - murani@fbn-dummerstorf.de; Mária Murániová - mmurani@web.de; Siriluck Ponsuksili - s.wimmers@fbndummerstorf.de; Karl Schellander - karl.schellander@itw.uni-bonn.de; Klaus Wimmers* - wimmers@fbn-dummerstorf.de

* Corresponding author

Published: I October 2007

BMC Developmental Biology 2007, 7:109 doi:10.1/86/147|-213X-7-109
Received: 12 February 2007

Accepted: I October 2007

This article is available from: http://www.biomedcentral.com//47/-2/3X/7//09

(C) 2007 Muráni et al; licensee BioMed Central Ltd.

This is an Open Access article distributed under the terms of the Creative Commons Attribution License (http://creativecommons.org/licenses/by/2.0), which permits unrestricted use, distribution, and reproduction in any medium, provided the original work is properly cited.

\begin{abstract}
Background: Postnatal muscle growth is largely depending on the number and size of muscle fibers. The number of myofibers and to a large extent their metabolic and contractile properties, which also influence their size, are determined prenatally during the process of myogenesis. Hence identification of genes and their networks governing prenatal development of skeletal muscles will provide insight into the control of muscle growth and facilitate finding the source of its variation. So far most of the genes involved in myogenesis were identified by in vitro studies using gene targeting and transgenesis. Profiling of transcriptome changes during the myogenesis in vivo promises to obtain a more complete picture. In order to address this, we performed transcriptome profiling of prenatal skeletal muscle using differential display RT-PCR as on open system with the potential to detect novel transcripts. Seven key stages of myogenesis (days I4, 2I, 35, 49, 63, 77 and 91 post conception) were studied in two breeds, Pietrain and Duroc, differing markedly in muscularity and muscle structure.
\end{abstract}

Results: Eighty prominent cDNA fragments were sequenced, 43 showing stage-associated and 37 showing breed-associated differences in the expression, respectively. Out of the resulting 85 unique expressed sequence tags, EST, 52 could be assigned to known genes. The most frequent functional categories represented genes encoding myofibrillar proteins (8), genes involved in cell adhesion, cell-cell signaling and extracellular matrix synthesis/remodeling (8), genes regulating gene expression (8), and metabolism genes (8). Some of the EST that showed no identity to any known transcripts in the databases are located in introns of known genes and most likely represent novel exons (e.g. HMGA2). Expression of thirteen transcripts along with five reference genes was further analyzed by means of real-time quantitative PCR. Nine of the target transcripts showed higher than twofold differences in the expression between the two breeds (GATA3, HMGA2, NRAP, SMC6LI, SPPI, RAB6IP2, TJPI and two EST).

Conclusion: The present study revealed several genes and novel transcripts not previously associated with myogenesis and expands our knowledge of genetic factors operating during myogenesis. Genes that exhibited differences between the divergent breeds represent candidate genes for muscle growth and structure. 


\section{Background}

Prenatal development of skeletal muscle, myogenesis, is an ideal model to study cell determination and differentiation. Accordingly myogenesis has become an extensively studied process in model animals [1]. Because muscle regeneration resembles myogenesis the study of myogenesis provides basic knowledge for the development of therapies to treat human muscle disease [2]. In farm animal biology the interest in myogenesis is driven mainly by the perception that muscle growth potential is associated with muscle fiber number and muscle structure, i.e. with characteristics that are determined prenatally during myogenesis [3]. The relationship between muscle mass and muscle fiber number as well as muscle structure is well illustrated by the observation that domestic pigs selected for muscularity exhibit a higher number of myofibers and an increased proportion of fast twitch glycolytic fibers (the myofiber type with the largest cross sectional area in the pig) compared to their wild ancestor or unimproved breeds [3,4]. Morphological studies of myogenesis in the pig are scarce. Development of somites takes place approximately between day 14 and 22 of gestation. Around day 35 of gestation the formation of primary myotubes starts and proceeds until around day 60 . The secondary population of myotubes appears around day 50 (45-54) on the surface of the primary myotubes, which they use as a scaffold. The number of secondary myotubes increases several fold until day 75 . Afterwards the number increases only slightly. Around days 85-90 the fiber formation ceases and the total number of fibers is established. The process of maturation of the myotubes into myofibers is finished in the early postnatal period $[5,6]$. In the pig, primary myotubes are a minor constituent of muscle fibers. In adult muscle, the ratio of primary to secondary myotubes is about 1:20. However, both populations of myotubes significantly influence fiber number and consequently muscle size. The importance of both primary and secondary myotubes for muscle growth is underscored by the lower number of primary fibers and a lower secondary to primary fiber ratio in small compared to large pig breeds $[7,8]$.

Knowledge of genetic and epigenetic factors that govern formation of both generations of myotubes will facilitate the understanding of the control of muscle growth and structure. Application of transcriptome profiling technologies largely enhances our knowledge of these factors and facilitates uncovering the myogenic gene networks. So far transcriptome profiling of myogenesis in livestock was performed using macroarrays $[9,10]$ or application specific microarrays [11-13]. However, only a limited number of specified genes could be analyzed using these methodologies.
In the present study we employed a complementary methodology, differential display RT-PCR, as an open system that facilitates the identification and the analysis of yet unknown transcripts. We analyzed myogenesis in two breeds differing in muscularity and muscle structure: the Pietrain breed with higher muscularity, higher number of muscle fibers and a higher proportion of glycolytic muscle fibers and the Duroc breed with lower muscularity and higher proportion of slow twitch muscle fibers $[4,14]$. The aim of this study was the identification of genes and pathways whose expression profile during development of porcine skeletal muscle implicates their involvement in myogenesis. In addition genes that were found to be differentially expressed between Pietrain and Duroc represent candidate genes with potential impact on muscle growth and structure.

\section{Results \\ Differential display RT-PCR profiling of the transcriptome during porcine myogenesis}

Comparison of a total of 88 differential display profiles between stages and between breeds revealed 458 cDNA fragments differing in their presence and/or in their intensity. Out of these, 310 cDNA fragments showed similar stage-associated differences in the expression in both breeds and 148 fragments were differentially displayed between breeds. Though the essentially binary expression patterns and the inefficient and tedious cloning of the differentially displayed cDNA fragments hamper a global view of the expression changes and a comprehensive pathway analysis, we attempted to assign cDNA fragments to groups based on their expression patterns and to relate these to functional pathways. Stage-associated cDNA fragments were classified into five groups of patterns ('period' groups) according to their distribution and/or changes in the intensity between the stages. The first group is related to early development (period 1; either present only or apparently upregulated at $14 \mathrm{dpc}$ and $21 \mathrm{dpc}$ ). The second and third groups are related to the first wave (period 2; either present only or apparently upregulated at $14-49$ $\mathrm{dpc}$ ) and the second wave (period 3; either present only or apparently upregulated at $49-91 \mathrm{dpc}$ ) of myogenesis respectively. The fourth group included fragments present at both first and the second wave of myogenesis (period 4; either present only or apparently upregulated at $21-91$ $\mathrm{dpc}$ ). The fifth group contained fragments present at all 7 stages that showed either steady up- or downregulation (period 5). In order to perform a similar grouping of the breed-associated cDNA fragments according to their temporal expression across stages one such fragment was called present at a particular stage if it was present in one of the two breeds (under the assumption that the absence in the other breed was due to lower expression level or a SNP in the priming site). 
Reamplification, cloning and sequencing was successfully performed for 43 breed- and 37 stage-associated cDNA fragments (Tables 1 and 2). Two breed-associated and four stage-associated differential display bands were found to represent multiple (2-3) different cDNA fragments of nearly identical length. The sequences of the cDNA fragments bR21D1 and bR10D1 were embedded in the larger EST bS19C1 and qR10D1, respectively, thus in total 85 unique EST ( 44 breed- and 41 stage- associated) were generated [GenBank:DQ631863, EH792585EH792670]. Homology search revealed that 45 EST represented known genes, 20 EST showed similarity to other anonymous EST/CDNA in the database, 3 EST showed similarity to genomic clones, 2 EST were homologous to mitochondrial DNA (genes) and 17 EST did not match any database entries. The MALAT1 gene was represented by two different EST representing cDNA fragments with similar expression patterns (qR24B1 and bS22B1\#2; period 4). Taking advantage of the high homology between pig and human sequences, we could assign 8 EST similar to anonymous EST/CDNA and 2 EST with genome hits to gene loci by BLAST search of the human genome. In total 55 EST were assigned to 52 genes.

The most frequent functional categories represented genes encoding myofibrillar genes (8 genes: MYH3, MYH1, TNNI2, MYPN, MYH2, TTN, NRAP, TPM1), genes involved in cell adhesion, cell-cell signaling and extracellular matrix synthesis/remodeling (8 genes: SDC3, LAMB1, SSPN, IGSF1, SPARCL1, SPP1, TIMP2, TJP1), genes regulating gene expression (8 genes: BICC1, GATA3, HMGA2, HMGN1, JMJD2A, RABGIP2, SETBP1, SMAD7) and metabolism genes (8 genes: ARNIP, GLUD1,LTB4DH, LXN, ND2, ND4L, NDUFA10, RPL37). The myofibrillar genes and genes involved in cell adhesion, cell-cell signaling and extracellular matrix synthesis/remodeling were almost exclusively represented in the period 4 group (i.e. they were expressed from 21-35 dpc onward).

Another functional group enriched in the period 4 group were cytoskeletal genes related to assembly of actin filaments (3 genes: ACTC, CFL2, SYNE2). The remaining functional groups showed no obvious enrichment in a specific period group.

Regarding the breed-associated cDNA fragments, 28 were present/more intense in Pietrain and 15 were present/ more intense in Duroc (Table 2). Genes related to cell adhesion, cell-cell signaling and extracellular matrix synthesis/remodeling and those from period group 4 tended to be enriched among the Pietrain differentials and genes related to metabolism and those from period group 2 tended to be enriched among the Duroc differentials.

\section{Analysis of expression profiles of reference genes}

The use of reference genes for normalization of real-time quantitative PCR (qPCR) data requires identification of genes which show constant expression under given experimental conditions. We analyzed expression profile of five potential reference genes, three (ACTB, RPL32, POLR2A) widely used and described $[15,16]$, and two (AGPAT1 involved in phospholipid metabolism and CANX involved in protein folding) showing stable expression in microarray studies comparing expression signatures of different tissues and/or developmental stages $[17,18]$. Not unexpectedly, considering the major changes in the cell type composition and the structure of the tissue samples, none of the five genes turned out to be expressed at constant levels across the seven prenatal stages (Figure 1). Expression of ACTB, POLR2A, CANX showed steady downregulation from $14 \mathrm{dpc}$ onwards, whereas expression of RPL32 and AGPAT1 peaked at $21 \mathrm{dpc}$ and was downregulated thereafter. All three reference genes analyzed in adult muscle (RPL32, AGPAT1, CANX) were downregulated compared to prenatal stages. Therefore we calculated a normalization factor based on the five reference genes (three for adult muscle) within stages, thus accounting for technical variation between breeds but not between stages.

\section{Validation of stage- and/or breed-associated differential expression of individual genes}

In previous expression studies performed in our laboratory using differential display RT-PCR the incidence of false positives was low with about 23\% [19], however, in other studies employing differential display RT-PCR the rate of false positives reached as much as $~ 80 \%$ in some cases [20]. Therefore expression patterns of thirteen genes showing stage- and/or breed-associated differential expression were validated by qPCR. We focused the validation mainly on the breed-associated genes because they represent primary candidates for finding the source of variation in muscularity and meat quality in pigs. All genes were selected so that (1) different expression patterns and/ or (2) different functional pathways were represented.

Three stage-associated genes, namely NME, IGSF1 and HMGA, were validated.

Expression of NME1 showed steady downregulation from $21 \mathrm{dpc}$ onward (Figure 1F).

Expression of IGSF1 was low/absent at $14 \mathrm{dpc}$, increased dramatically until $63 \mathrm{dpc}$, stayed at similar level until 91 $\mathrm{dpc}$ and was downregulated in adult muscle nearly to the starting level at $14 \mathrm{dpc}$ (Figure 1G). At all stages the differences in expression of NME1 and IGSF1 between Pietrain and Duroc were lower than twofold. 
Table I: Summary of EST showing stage-associated differential expression during porcine myogenesis

\begin{tabular}{|c|c|c|c|c|c|c|c|c|}
\hline EST/Clone & $\begin{array}{l}\text { Accession } \\
\text { number }\end{array}$ & IdentityI & Species & $\begin{array}{l}\text { Accession } \\
\text { number }\end{array}$ & Similarity & Function & $\begin{array}{l}\text { Period } \\
\text { group }\end{array}$ & $\begin{array}{l}\text { Expression } \\
\text { pattern }^{2}\end{array}$ \\
\hline bS9C3 & EH792591 & Syndecan 3 (SDC3) & Bovine & XM 870523 & I06/I27 (83\%) & $\begin{array}{l}\text { cell adhesion, } \\
\text { ECM }\end{array}$ & 1 & I-I-0-0-0-0-0 \\
\hline bSI7A2 & EH792585 & $\begin{array}{l}\text { Ribosomal protein L37a } \\
\text { (RPL37A) }\end{array}$ & Canine & AY197363.1 & | 46/I72 (84\%) & metabolism & I & $0-I>I-I-I-I-I$ \\
\hline bS24A4 & EH792589 & $\begin{array}{l}\text { Glutamate } \\
\text { dehydrogenase I } \\
\text { (GLUDI) }\end{array}$ & Human & X67491.I & I57/I73 (90\%) & metabolism & 1 & I-I-0-0-0-0-0 \\
\hline bS9BI & EH792590 & EST & Porcine & BE235673 & $237 / 283(83 \%)$ & other, unknown & 1 & I- $0-0-0-0-0-0$ \\
\hline bSI7C2 & $\underline{E H 792586}$ & Unknown & & & & other, unknown & I & $0-1-0-0-0-0-0$ \\
\hline bSI7D3 & $\underline{E H 792587}$ & EST & Bovine & CBI69367 & I46/I 69 (86\%) & other, unknown & I & $0-1-0-0-0-0-0$ \\
\hline bS18D2 & EH792588 & Unknown & & & & other, unknown & I & $|-|-0-0-0-0-0$ \\
\hline bS8DI & EH792602 & $\begin{array}{l}\text { ATG3 autophagy related } \\
3 \text { homolog (S. cerevisiae) } \\
\text { (ATG3) }\end{array}$ & Human & NM 022488 & $132 / 146(90 \%)$ & $\begin{array}{l}\text { cell death, } \\
\text { autophagy }\end{array}$ & 2 & $0-1-1-0-0-0-0$ \\
\hline bS9C4 & $\underline{\mathrm{EH} 792603}$ & $\begin{array}{l}\text { EST, [Insulin-like growth } \\
\text { factor binding protein- } \\
\text { like I (IGFBPLI)] }\end{array}$ & Porcine & CK465405 & $202 / 205$ (98\%) & cell proliferation & 2 & $0-1>1-0-0-0-0$ \\
\hline bS24D3\#2 & EH792596 & $\begin{array}{l}\text { Non-metastatic cells I, } \\
\text { protein (NM23A) } \\
\text { expressed in (NMEI) }\end{array}$ & Human & $\frac{N M 198175 .}{1}$ & $333 / 387(86 \%)$ & cell proliferation & 2 & $|-|-|-|>|-|-\mid$ \\
\hline bS2B3\#I & EH792598 & $\begin{array}{l}\text { Mitochondrion, [NADH } \\
\text { dehydrogenase subunit } \\
\text { 4L (ND4L)] }\end{array}$ & Porcine & AY334492 & $146 / 146$ (100\%) & metabolism & 2 & $0-I-I-I-0-0-0$ \\
\hline bS2B3\#2 & EH792599 & $\begin{array}{l}\text { Signal sequence receptor, } \\
\text { gamma (SSR3) }\end{array}$ & Human & NM 007107 & $82 / 90(91 \%)$ & other, unknown & 2 & $0-I-I-I-0-0-0$ \\
\hline bS2B4 & EH792600 & $\begin{array}{l}\text { 5'-nucleotidase domain } \\
\text { containing } 2 \text { (NT5DC2) }\end{array}$ & Human & $\underline{\mathrm{BC} 014550.1}$ & $120 / 130(92 \%)$ & other, unknown & 2 & $0-|-|-\mid-0-0-0$ \\
\hline bS2BI & EH792597 & Unknown & & & & other, unknown & 2 & $0-|-|-\mid-0-0-0$ \\
\hline bS24D3\#I & $\overline{\mathrm{EH} 792595}$ & EST & Porcine & BG835728 & $122 / 123(99 \%)$ & other, unknown & 2 & $|-|-|-|>|-|-\mid$ \\
\hline bS3D7 & EH79260I & $\begin{array}{l}\text { High mobility group AT- } \\
\text { hook } 2 \text { (HMGA2) }\end{array}$ & Human & AF326972 & 198/235 (84\%) & $\begin{array}{l}\text { regulation of } \\
\text { transcription }\end{array}$ & 2 & $0-1>1>|-|-|-|$ \\
\hline bS9C7 & EH792614 & $\begin{array}{l}\text { Homo sapiens genomic } \\
\text { DNA, chromosome I I q, } \\
\text { clone:CTD-20I IFI7, } \\
\text { [UV radiation resistance } \\
\text { associated gene } \\
\text { (UVRAG)] }\end{array}$ & Human & AP002340 & $58 / 67(86 \%)$ & $\begin{array}{l}\text { cell death, } \\
\text { autophagy }\end{array}$ & 3 & $0-0-0-0-I-I-I$ \\
\hline qS24D2 & EH792616 & $\begin{array}{l}\text { Tropomyosin I, alpha } \\
\text { (TPMI) }\end{array}$ & Porcine & $\underline{X 66274.1}$ & $373 / 376(99 \%)$ & $\begin{array}{l}\text { myofibrill } \\
\text { assembly }\end{array}$ & 3 & $0-I-I<I-I-I-I$ \\
\hline $\mathrm{bS} 15 \mathrm{C} 2$ & EH792628 & $\begin{array}{l}\text { TIMP metallopeptidase } \\
\text { inhibitor } 2 \text { (TIMP2) }\end{array}$ & Porcine & AFI56030 & |46/I78 (82\%) & $\begin{array}{l}\text { cell adhesion, } \\
\text { ECM }\end{array}$ & 4 & $0-0-|-|-|-|-\mid$ \\
\hline $\mathrm{bS} 19 \mathrm{Cl}$ & EH792632 & $\begin{array}{l}\text { Immunoglobulin } \\
\text { superfamily, member I } \\
\text { (IGSFI) }\end{array}$ & Canine & $\underline{X M \quad 538173.1}$ & $351 / 391$ (89\%) & $\begin{array}{l}\text { cell adhesion, } \\
\text { ECM }\end{array}$ & 4 & $0-1<1-I-|-|-\mid$ \\
\hline bS3D8 & EH792642 & $\begin{array}{l}\text { Actin, alpha, cardiac } \\
\text { muscle (ACTC) }\end{array}$ & Human & $\frac{N M 005159 .}{\underline{3}}$ & I72/I84 (93\%) & cell structure & 4 & $0-|-|-|-|-|-|$ \\
\hline bSI4D2 & EH792627 & Cofilin 2, muscle (CFL2) & Human & $\frac{N M \quad 138638 .}{1}$ & $128 / 139(92 \%)$ & cell structure & 4 & $0-0-I-I-I-I-I$ \\
\hline bS20A3 & EH792635 & $\begin{array}{l}\text { Myosin, heavy } \\
\text { polypeptide I, skeletal } \\
\text { muscle, adult (MYHI) }\end{array}$ & Porcine & $\mathrm{AB} 025262$ & $237 / 245$ (96\%) & $\begin{array}{l}\text { myofibrill } \\
\text { assembly }\end{array}$ & 4 & $0-0-1-1-1-1-1$ \\
\hline bSIB3 & $\underline{\mathrm{EH}} 792633$ & $\begin{array}{l}\text { Troponin I type 2, } \\
\text { skeletal, fast (TNNI2) }\end{array}$ & Porcine & $\frac{\text { NM } 0010323}{59}$ & $50 / 5 I(98 \%)$ & $\begin{array}{l}\text { myofibrill } \\
\text { assembly }\end{array}$ & 4 & $0-0-|-|-|-|-\mid$ \\
\hline$b S|8 B|$ & EH792631 & Myopalladin (MYPN) & Canine & $\underline{X M 546131.1}$ & $96 / 100$ (96\%) & $\begin{array}{l}\text { myofibrill } \\
\text { assembly }\end{array}$ & 4 & $0-0-|-|-|-|-\mid$ \\
\hline bSI4C4 & EH792626 & $\begin{array}{l}\text { Myosin, heavy } \\
\text { polypeptide } 3 \text {, skeletal } \\
\text { muscle, embryonic } \\
\text { (MYH3) }\end{array}$ & Bovine & AB090155.I & $292 / 312$ (93\%) & $\begin{array}{l}\text { myofibrill } \\
\text { assembly }\end{array}$ & 4 & $0-1<1-I-I-I-I$ \\
\hline bSI5C4 & EH792629 & $\begin{array}{l}\text { Myosin, heavy } \\
\text { polypeptide } 2(\mathrm{MYH} 2)\end{array}$ & Porcine & $\frac{N M 214136 .}{1}$ & $249 / 270(92 \%)$ & $\begin{array}{l}\text { myofibrill } \\
\text { assembly }\end{array}$ & 4 & $0-0-1-I-I>1>1$ \\
\hline
\end{tabular}


Table I: Summary of EST showing stage-associated differential expression during porcine myogenesis (Continued)

\begin{tabular}{|c|c|c|c|c|c|c|c|c|}
\hline qS4D7 & EH792660 & Titin (TTN) & Human & $\frac{N M 003319 .}{2}$ & $318 / 353(90 \%)$ & $\begin{array}{l}\text { myofibrill } \\
\text { assembly }\end{array}$ & 4 & $0-0-1<1<|-|-\mid$ \\
\hline bS4B3 & $\underline{\mathrm{EH} 792643}$ & Unknown & & & & other, unknown & 4 & $0-0-1-1-1-1-1$ \\
\hline bS22BI\#I & $\underline{\mathrm{EH} 792636}$ & $\begin{array}{l}\text { EST [Chromosome } 6 \\
\text { open reading frame } 89 \\
\text { (C6orf89)] }\end{array}$ & Porcine & BPI4202I & $|47 /| 5 \mid$ (97\%) & other, unknown & 4 & $0-0-|-|-|-|-\mid$ \\
\hline bS22BI\#2 & EH792637 & $\begin{array}{l}\text { Metastasis associated } \\
\text { lung adenocarcinoma } \\
\text { transcript I (MALATI) }\end{array}$ & Human & NR 002819 & $204 / 240$ (85\%) & other, unknown & 4 & $0-0-1-1-1-1-1$ \\
\hline bS26B3 & $\underline{\mathrm{EH} 792640}$ & EST & Porcine & BX918881 & $52 / 55(94 \%)$ & other, unknown & 4 & $0-0-1-1-1-1-1$ \\
\hline bS22C2\#I & EH792638 & EST & Porcine & BQ599825 & $98 / 106(92 \%)$ & other, unknown & 4 & $0-I<|-|-|-|-\mid$ \\
\hline bS22C2\#2 & EH792639 & EST & Porcine & CB473363 & $90 / 105$ (85\%) & other, unknown & 4 & $0-|<|-|-|-|-|$ \\
\hline bSI2DI & $\underline{\mathrm{EH} 792624}$ & EST & Porcine & CV866720 & $191 / 204$ (93\%) & other, unknown & 4 & $0-I<|-|-|-|-\mid$ \\
\hline bSI7B3 & EH792630 & $\begin{array}{l}\text { High-mobility group } \\
\text { nucleosome binding } \\
\text { domain I (HMGNI) }\end{array}$ & Canine & BX641076 & $292 / 308$ (94\%) & $\begin{array}{l}\text { regulation of } \\
\text { transcription }\end{array}$ & 4 & $\begin{array}{l}0-1<1<1<1< \\
1<1\end{array}$ \\
\hline bSI4C2 & EH792625 & $\begin{array}{l}\text { DEP domain containing } 5 \\
\text { (DEPDC5) }\end{array}$ & Human & BC057797.1 & $189 / 206$ (91\%) & $\begin{array}{l}\text { signal } \\
\text { transduction }\end{array}$ & 4 & $0-0-I-I-I-I-I$ \\
\hline bS20A2 & EH792634 & $\begin{array}{l}\text { ATP synthase, } \mathrm{H}+ \\
\text { transporting, } \\
\text { mitochondrial FI } \\
\text { complex, gamma } \\
\text { polypeptide I (ATP5CI) }\end{array}$ & Bovine & $\underline{X M ~} 873667$ & $177 / 195$ (90\%) & transport & 4 & $0-0-I-I-I-I-I$ \\
\hline bS2DI & EH79264I & Hemoglobin, beta (HBB) & Porcine & X86791 & $191 / 197$ (96\%) & transport & 4 & $0-|<|-|-|-|-|$ \\
\hline qS20AI & $\mathrm{EH} 792670$ & $\begin{array}{l}\text { Mitochondrion, [NADH- } \\
\text { ubiquinone } \\
\text { oxidoreductase chain2 } \\
\text { (ND2)] }\end{array}$ & Rabbit & AJ012536 & $237 / 240(98 \%)$ & metabolism & 5 & $\begin{array}{l}|-|>1>1>1> \\
\mid>1\end{array}$ \\
\hline qSI5DI & EH792669 & Ataxin 10 (ATXNI0) & Porcine & AY550076 & 169/193 (87\%) & other, unknown & 5 & $\begin{array}{l}1>1>1>1>1 \\
>1-1\end{array}$ \\
\hline
\end{tabular}

\footnotetext{
IIn square brackets the identity derived by cross-species megaBLAST search of the human genome sequence is indicated
}

2 Binary coding of the differential display RT-PCR pattern (I-present, 0 -absent)

Expression of HMGA2 was barely detectable at $14 \mathrm{dpc}$, reached maximum at 21-35 dpc, decreased substantially at $49 \mathrm{dpc}$, stayed at similar low level until $91 \mathrm{dpc}$ and was essentially shut down in adult muscle (Figure $1 \mathrm{H}$ ). The sensitive qPCR revealed a 2 .5-fold higher expression of HMGA2 in Pietrain at $49 \mathrm{dpc}$, not detected by differential display RT-PCR.

The expression patterns of ten breed-associated genes and EST were validated.

Expression of GATA3 as revealed by qPCR was highest at $14 \mathrm{dpc}$ (Figure 2A). At $21 \mathrm{dpc}$ the expression decreased, with more pronounced downregulation in Duroc embryos. In agreement with the results of differential display RT-PCR the expression lasted in Duroc embryos/ fetuses until 49 dpc whereas in Pietrain embryos/fetuses the expression ceased already at $35 \mathrm{dpc}$.

The EST bR24D1, that was found in Duroc from $35 \mathrm{dpc}$ onward only, was homologous to intron 6 of the SPP1 gene. Since we used total RNA for differential display RTPCR we reasoned that this EST was derived from heteronuclear RNA (hnRNA) and thereby reflected higher active transcription of SPP1 in Duroc. QPCR using exon specific primers showed that expression of SPP1 peaked at 35 and $77 \mathrm{dpc}$, i.e. at the time-points of the two myogenic waves, and confirmed consistently higher expression of SPP1 in Duroc at all seven prenatal stages (Figure 2B). The difference was highest at $14 \mathrm{dpc}$ ( 20-fold), afterwards gradually decreased until $49 \mathrm{dpc}$ ( 3.6-fold to $\sim 1.3$-fold) and remained at similar magnitude until $91 \mathrm{dpc}$. In adult muscle no differences were found.

The SMC6L1 gene was expressed throughout myogenesis as shown consistently by both, differential display RTPCR and qPCR (Figure 2C). QPCR revealed more than twofold upregulation of SMC6L1 at 35 and 49 dpc in Pietrain in agreement with differential display RT-PCR and additionally at $91 \mathrm{dpc}$, but no difference was found at 14 dpc.

For the remaining breed-associated EST/genes no clear relationship between profiles obtained using differential display RT-PCR and qPCR respectively could be established.

The expression profile of RAB6IP2 showed two peaks, one higher at 21-35 dpc and another at $63 \mathrm{dpc}$, i.e. at the onset of the two waves of myofiber formation. Expression 
Table 2: Summary of EST showing differences in expression during myogenesis between Pietrain and Duroc breeds of pigs

\begin{tabular}{|c|c|c|c|c|c|c|c|c|}
\hline EST/Clone & $\begin{array}{l}\text { Accession } \\
\text { number }\end{array}$ & Identity' & Species & $\begin{array}{l}\text { Accession } \\
\text { number }\end{array}$ & Similarity & Function & $\begin{array}{l}\text { Period } \\
\text { group }\end{array}$ & $\begin{array}{l}\text { Expression } \\
\text { pattern }{ }^{2}\end{array}$ \\
\hline qRI5AI\#2 & EH792605 & $\begin{array}{l}\text { Androgen receptor } \mathrm{N} \text { - } \\
\text { terminal-interacting protein } \\
\text { (ARNIP) }\end{array}$ & Human & AF247041 & $254 / 267(95 \%)$ & metabolism & 2 & D-I-D-0-0-0-0 \\
\hline qRI5AI\#3 & EH792606 & $\begin{array}{l}\text { NADP dependent leukotriene } \\
\text { b4 I2-hydroxydehydrogenase } \\
\text { (LTB4DH) }\end{array}$ & Porcine & NM 214385 & $235 / 243(96 \%)$ & metabolism & 2 & D-I-D-0-0-0-0 \\
\hline qR8AI & $\underline{E H 792608}$ & Unknown & & & & $\begin{array}{l}\text { other, } \\
\text { unknown }\end{array}$ & 2 & D-D-D-0-0-0-0 \\
\hline bR9Cl & EH792594 & Unknown & & & & $\begin{array}{l}\text { other, } \\
\text { unknown }\end{array}$ & 2 & D-D-D-D-0-0-0 \\
\hline $\mathrm{qR} 24 \mathrm{Cl}$ & EH792607 & $\begin{array}{l}\text { Pan troglodytes chromosome } \\
22 \text { clone:RP43-009002 }\end{array}$ & Chimp & $\mathrm{BS} 000013$ & $92 / 112(82 \%)$ & $\begin{array}{l}\text { other, } \\
\text { unknown }\end{array}$ & 2 & D-I-D-0-0-0-0 \\
\hline bR4DI & $\underline{\mathrm{EH} 792593}$ & Unknown & & & & $\begin{array}{l}\text { other, } \\
\text { unknown }\end{array}$ & 2 & $0-1-D-0-0-0-0$ \\
\hline $\mathrm{bR} \mid 3 \mathrm{~B} 4$ & $\underline{\mathrm{EH}} 792592$ & $\begin{array}{l}\text { GATA binding protein } 3 \\
\text { (GATA3) }\end{array}$ & Porcine & DQ45090I & 189/193 (97\%) & $\begin{array}{l}\text { regulation of } \\
\text { transcription }\end{array}$ & 2 & I-I-D-0-0-0-0 \\
\hline qRI5AI\#I & EH792604 & $\begin{array}{l}\text { DEAD (Asp-Glu-Ala-Asp) box } \\
\text { polypeptide } 17 \text { (DDXI7) }\end{array}$ & Human & NM 030881 & $230 / 259(88 \%)$ & $\begin{array}{l}\text { RNA/DNA } \\
\text { metabolism }\end{array}$ & 2 & D-I-D-0-0-0-0 \\
\hline bR2IDI & $\underline{\mathrm{EH} 792610}$ & $\begin{array}{l}\text { Immunoglobulin superfamily, } \\
\text { member I (IGSFI) }\end{array}$ & Canine & $\underline{X M \quad 538173}$ & 199/2I 2 (93\%) & $\begin{array}{l}\text { cell adhesion, } \\
\text { ECM }\end{array}$ & 3 & $0-0-0-0-0-P-P$ \\
\hline bR2BI & $\underline{E H 7926 I I}$ & Unknown & & & & $\begin{array}{l}\text { other, } \\
\text { unknown }\end{array}$ & 3 & $0-0-0-I-I-P-0$ \\
\hline bR8B2 & $\underline{E H 792613}$ & Unknown & & & & $\begin{array}{l}\text { other, } \\
\text { unknown }\end{array}$ & 3 & $0-0-0-0-0-P-P$ \\
\hline bRI8DI & EH792609 & Unknown & & & & $\begin{array}{l}\text { other, } \\
\text { unknown }\end{array}$ & 3 & $0-0-0-0-D-I-I$ \\
\hline bR7DI & $\underline{\mathrm{EH} 792612}$ & $\begin{array}{l}\text { RAB6 interacting protein } 2 \\
\text { (RAB6IP2) }\end{array}$ & Human & NM 178037 & $268 / 287(93 \%)$ & $\begin{array}{l}\text { regulation of } \\
\text { transcription }\end{array}$ & 3 & $0-0-0-0-D-I-I$ \\
\hline qR7B2 & $\underline{E H 792615}$ & $\begin{array}{l}\text { Rap guanine nucleotide } \\
\text { exchange factor (GEF) } 5 \\
\text { (RAPGEF5) }\end{array}$ & Human & $\underline{\mathrm{BC} 039203}$ & $62 / 73(84 \%)$ & $\begin{array}{l}\text { signal } \\
\text { transduction }\end{array}$ & 3 & 0-0-0-P-P-P-P \\
\hline qR3BI & EH792655 & EST [Laminin, beta I (LAMBI)] & Porcine & BE030491 & 17I/I74 (98\%) & $\begin{array}{l}\text { cell adhesion, } \\
\text { ECM }\end{array}$ & 4 & 0-P-P-P-I-I-I \\
\hline qR4D2 & EH792658 & EST [Sarcospan (SSPN)] & Porcine & BX924101 & $469 / 475(98 \%)$ & $\begin{array}{l}\text { cell adhesion, } \\
\text { ECM }\end{array}$ & 4 & $0-P-P-I-I-I-I$ \\
\hline qRI9DI & $\underline{E H 792650}$ & SPARC-like I (SPARCLI) & Human & NM 004684 & 198/236 (83\%) & $\begin{array}{l}\text { cell adhesion, } \\
\text { ECM }\end{array}$ & 4 & 0-0-P-P-P-P-P \\
\hline qR22DI & EH792652 & Tight junction protein I (TJPI) & Human & NM 003257 & $447 / 486(91 \%)$ & $\begin{array}{l}\text { cell adhesion, } \\
\text { ECM }\end{array}$ & 4 & 0-0-P-P-P-0-0 \\
\hline bR24DI & EH792623 & $\begin{array}{l}\text { Secreted phosphoprotein I } \\
\text { (SPPI) }\end{array}$ & Porcine & A) 237667 & $125 / 126$ (99\%) & $\begin{array}{l}\text { cell adhesion, } \\
\text { ECM }\end{array}$ & 4 & 0-0-D-D-D-D-D \\
\hline qRI4AI\#2 & EH792645 & $\begin{array}{l}\text { Spectrin repeat containing, } \\
\text { nuclear envelope } 2 \text { (SYNE2) }\end{array}$ & Human & $\mathrm{BC} 042134$ & $88 / 100(88 \%)$ & cell structure & 4 & 0-0-I-D-D-D-D \\
\hline qRIAI & EH79265I & $\begin{array}{l}\text { NADH dehydrogenase } \\
\text { (ubiquinone) I alpha } \\
\text { subcomplex } 10 \text { (NDUFA I0) }\end{array}$ & Bovine & NM 176655 & $84 / 90(93 \%)$ & metabolism & 4 & $0-0-I-I-I-I-D$ \\
\hline qRI4AI\#I & EH792644 & Latexin $(\mathrm{LXN})$ & Human & BC008438 & $|33 /| 5 \mid(88 \%)$ & metabolism & 4 & 0-0-I-D-D-D-D \\
\hline $\mathrm{bR} \mid 3 \mathrm{~B} 8$ & $\underline{\mathrm{EH} 792618}$ & $\begin{array}{l}\text { Nebulin-related anchoring } \\
\text { protein (NRAP) }\end{array}$ & Porcine & DQ157553 & 199/200 (99\%) & $\begin{array}{l}\text { myofibrill } \\
\text { assembly }\end{array}$ & 4 & 0-P-P-P-P-P-0 \\
\hline bR24AI & EH792621 & Unknown & & & & $\begin{array}{l}\text { other, } \\
\text { unknown }\end{array}$ & 4 & O-P-P-P-P-P-P \\
\hline qR4BI & EH792656 & Unknown & & & & $\begin{array}{l}\text { other, } \\
\text { unknown }\end{array}$ & 4 & 0-P-P-P-I-I-I \\
\hline qR24BI & EH792653 & $\begin{array}{l}\text { Metastasis associated lung } \\
\text { adenocarcinoma transcript I } \\
\text { (MALATI) }\end{array}$ & Human & NR 002819 & $72 / 79$ (91\%) & $\begin{array}{l}\text { other, } \\
\text { unknown }\end{array}$ & 4 & $0-0-P-P-I-I-I$ \\
\hline qR25B3 & EH792654 & Unknown & & & & $\begin{array}{l}\text { other, } \\
\text { unknown }\end{array}$ & 4 & 0-0-P-P-P-P-P \\
\hline qR5Cl & EH792659 & EST & Porcine & CJ014638 & 195/228 (85\%) & $\begin{array}{l}\text { other, } \\
\text { unknown }\end{array}$ & 4 & $0-0-P-P-I-I-P$ \\
\hline $\mathrm{qRI5CI}$ & EH792647 & Unknown & & & & $\begin{array}{l}\text { other, } \\
\text { unknown }\end{array}$ & 4 & 0-D-P-P-P-0-0 \\
\hline
\end{tabular}


Table 2: Summary of EST showing differences in expression during myogenesis between Pietrain and Duroc breeds of pigs (Continued)

\begin{tabular}{|c|c|c|c|c|c|c|c|c|}
\hline qRI9CI & EH792649 & Unknown & & & & $\begin{array}{l}\text { other, } \\
\text { unknown }\end{array}$ & 4 & $0-0-P-P-I-I-I$ \\
\hline qR4DI & EH792657 & Unknown & & & & $\begin{array}{l}\text { other, } \\
\text { unknown }\end{array}$ & 4 & 0-P-P-P-I-I-I \\
\hline bRI5DI & EH792619 & EST & Porcine & A) 956602 & $45 / 48$ (93\%) & $\begin{array}{l}\text { other, } \\
\text { unknown }\end{array}$ & 4 & 0-0-P-P-P-P-P \\
\hline bR22D2 & $\underline{E H 792620}$ & EST & Bovine & AW344601 & $49 / 52$ (94\%) & $\begin{array}{l}\text { other, } \\
\text { unknown }\end{array}$ & 4 & 0-0-P-P-I-I-I \\
\hline$b R|3 B| 0$ & EH792617 & $\begin{array}{l}\text { EST [SMAD family member } 7 \\
\text { (SMAD7)] }\end{array}$ & Bovine & DV922547 & 61/67 (91\%) & $\begin{array}{l}\text { regulation of } \\
\text { transcription }\end{array}$ & 4 & O-P-P-O-P-P-P \\
\hline bR24C2 & EH792622 & $\begin{array}{l}\text { EST [SET binding protein I } \\
(\text { SETBPI)] }\end{array}$ & Porcine & BPI72194 & $369 / 373$ (98\%) & $\begin{array}{l}\text { regulation of } \\
\text { transcription }\end{array}$ & 4 & 0-P-P-P-P-P-P \\
\hline$q R \mid 4 C 2$ & $\underline{E H 792646}$ & $\begin{array}{l}\text { Heterogeneous nuclear } \\
\text { ribonucleoprotein D (HNRPD) }\end{array}$ & Murine & AK077409 & $265 / 279$ (94\%) & $\begin{array}{l}\text { RNA/DNA } \\
\text { metabolism }\end{array}$ & 4 & 0-0-P-P-P-P-P \\
\hline qRI7BI & EH792648 & $\begin{array}{l}\text { Homo sapiens I2 BAC RPI } \\
\text { I-729|10 [ABCC9] }\end{array}$ & Human & $\underline{\mathrm{AC} 008250}$ & 75/87 (86\%) & transport & 4 & 0-0-D-D-D-D-D \\
\hline bR22BI & EH792663 & $\begin{array}{l}\text { Platelet-derived growth factor } \\
\text { receptor, alpha polypeptide } \\
\text { (PDGFRA) }\end{array}$ & Human & NM 006206 & $252 / 287$ (87\%) & $\begin{array}{l}\text { cell } \\
\text { proliferation }\end{array}$ & 5 & D-D-D-D-D-D-D \\
\hline qR7BI & EH792668 & $\begin{array}{l}\text { SMC6 structural maintenance } \\
\text { of chromosomes 6-like I } \\
\text { (SMC6LI) }\end{array}$ & Canine & XM 532882 & $169 / 176(96 \%)$ & $\begin{array}{l}\text { other, } \\
\text { unknown }\end{array}$ & 5 & D-I-P-P-I-I-I \\
\hline bR26BI & EH792664 & Unknown & & & & $\begin{array}{l}\text { other, } \\
\text { unknown }\end{array}$ & 5 & P-P-P-P-I-P-I \\
\hline qRIODI & EH792666 & $\begin{array}{l}\text { cDNA FLJ26539 fis [Bicaudal C } \\
\text { homolog I (BICCI)] }\end{array}$ & Human & AKI30049 & 65/7। (91\%) & $\begin{array}{l}\text { regulation of } \\
\text { transcription }\end{array}$ & 5 & P-P-P-P-P-P-P \\
\hline bRIODI & DQ631863 & $\begin{array}{l}\text { cDNA FLJ26539 fis [Bicaudal C } \\
\text { homolog I (BICCI)] }\end{array}$ & Human & AKI30049 & 65/7I (9l\%) & $\begin{array}{l}\text { regulation of } \\
\text { transcription }\end{array}$ & 5 & D-D-D-D-D-D-D \\
\hline bRI2DI & $\underline{E H 79266 I}$ & EST & Porcine & A) 955354 & $5 \mathrm{I} / 5 \mathrm{I}(100 \%)$ & $\begin{array}{l}\text { other, } \\
\text { unknown }\end{array}$ & 5 & P-P-P-P-P-P-P \\
\hline qR20DI & $\underline{E H 792667}$ & EST & Porcine & DV230345 & $7|/ 7|(100 \%)$ & $\begin{array}{l}\text { other, } \\
\text { unknown }\end{array}$ & 5 & P-P-P-P-P-P-P \\
\hline bR2B2 & $\underline{E H 792665}$ & $\begin{array}{l}\text { Jumonji domain containing } 2 \mathrm{~A} \\
\text { (JMJD2A) }\end{array}$ & Canine & $\underline{X M \quad 539647}$ & 278/305 (91\%) & $\begin{array}{l}\text { regulation of } \\
\text { transcription }\end{array}$ & 5 & P-I-I-I-I-I-I \\
\hline$b R \mid 3 A 3$ & EH792662 & $\begin{array}{l}\text { Poly(A) polymerase gamma } \\
\text { (PAPOLG) }\end{array}$ & Bovine & XM 60751I & $217 / 229(94 \%)$ & $\begin{array}{l}\text { RNA/DNA } \\
\text { metabolism }\end{array}$ & 5 & D-D-D-D-D-D-D \\
\hline
\end{tabular}

In square brackets the identity derived by cross-species megaBLAST search of the human genome sequence is indicated

2Binary coding of the differential display RT-PCR pattern (I-present in both breeds, 0 -absent in both breeds, P-Present/More intense in Pietrain, DPresent/More intense in Duroc)

of RAB6IP2 was consistently upregulated ( 1.5 to 3fold) throughout myogenesis in Pietrain compared to Duroc with the most pronounced differences at 35-49 dpc ( 2.5 to 3-fold; Figure 2D).

The expression pattern of the EST bR22B1, homologous to PDGFRA, obtained by differential display RT-PCR suggested upregulation of PDGFRA in Duroc compared to Pietrain embryos/fetuses. Indeed such upregulation was found by qPCR at all stages but 35 and $49 \mathrm{dpc}$ when the situation was reversed (Figure 2E). The 1.2-1.4-fold upregulation of PDGFRA detected by qPCR in Duroc correlated poorly with the results of differential display RTPCR. However, qPCR revealed a striking difference in the expression pattern between Pietrain and Duroc. In Pietrain the expression of PDGFRA gene showed a peak at 35 $\mathrm{dpc}$ whereas in Duroc two peaks existed, one at $21 \mathrm{dpc}$ and another at $63 \mathrm{dpc}$.

For TJP1 both, differential display RT-PCR and qPCR indicated upregulation ( $\geq 2$-fold) at 35 and $49 \mathrm{dpc}$ in Pietrain compared to Duroc (Figure 2F). No difference at $63 \mathrm{dpc}$ could be shown by qPCR. The expression of TJP1 was highest at $14 \mathrm{dpc}$ and in Duroc continuously decreased until 49 dpc. In Pietrain a small peak at $35 \mathrm{dpc}$ was observed. From 63 dpc onward the expression stayed at a similar level until $91 \mathrm{dpc}$ in both breeds.

The expression profile of $L X N$ as revealed by qPCR (Figure $2 \mathrm{G})$ was similar to the expression profiles of RPL32 and AGPAT1 (Figure 1C and 1E). The differences in the expression of LXN between breeds were less than twofold, but especially in the early stages 21-49 dpc the expression was consistently higher in Pietrain.

The expression of NRAP, as revealed by qPCR, was barely detectable at $14 \mathrm{dpc}$ and continuously increased in the developing muscle until adult age (Figure 2H). At $35 \mathrm{dpc}$ the expression of NRAP was $\sim 2$-fold higher in Pietrain compared to Duroc fetuses. 

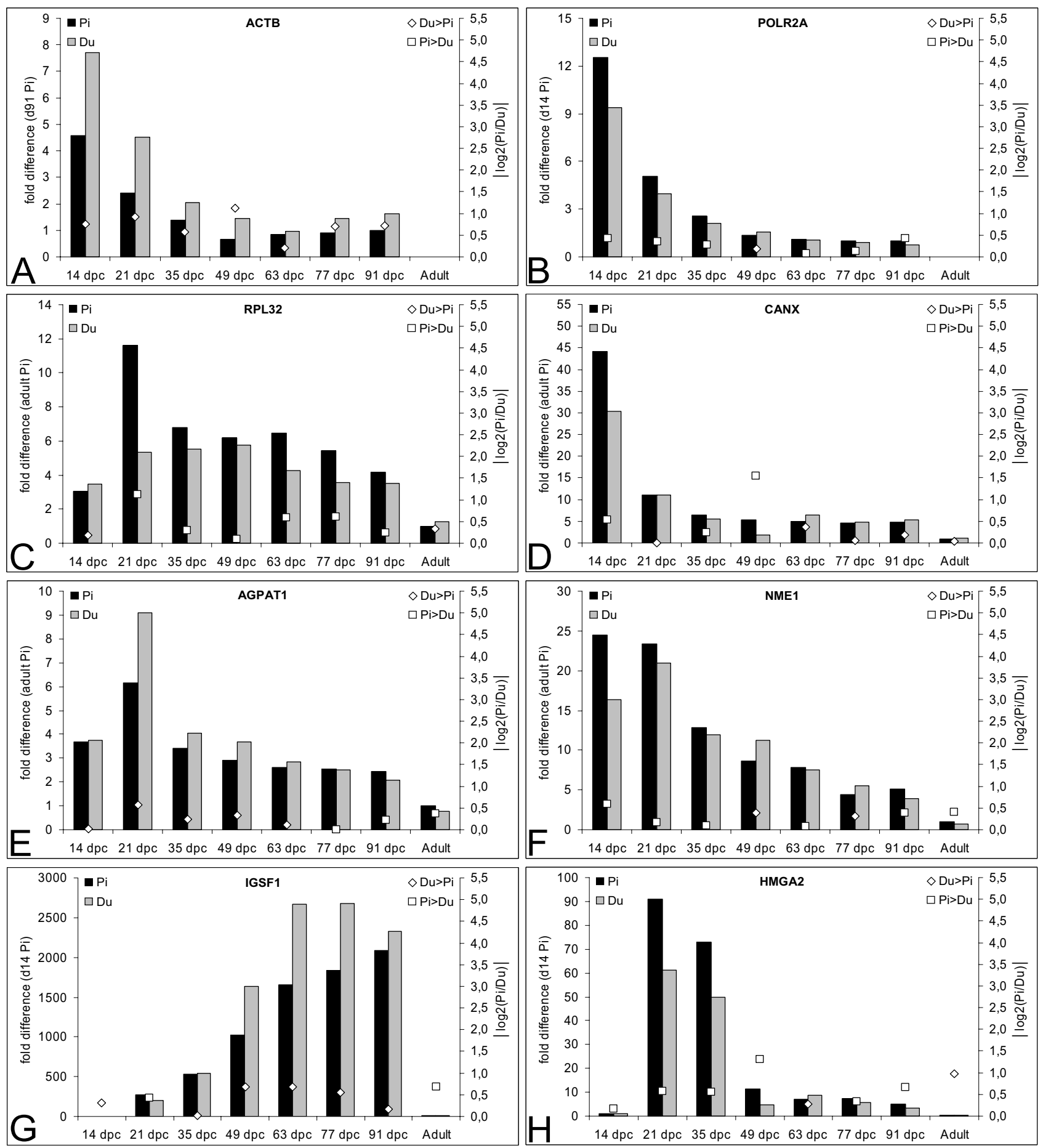

Figure I

Expression of reference genes (A-E) and genes showing stage-associated differential display RT-PCR patterns (F-H) obtained by qPCR. Histograms show normalized relative gene expression in Pietrain and Duroc embryos/Musculus longissimus dorsi at seven prenatal stages and in the adults (primary y-axis). For some genes data on expression in adults is missing. Open boxes and diamonds show absolute values of the Pietrain vs. Duroc expression ratios at each stage $(\log 2(\mathrm{Pi} / \mathrm{Du}))$.

Open diamonds indicate higher expression in Duroc compared to Pietrain individuals and open boxes indicate the reverse situation (secondary y-axis). 

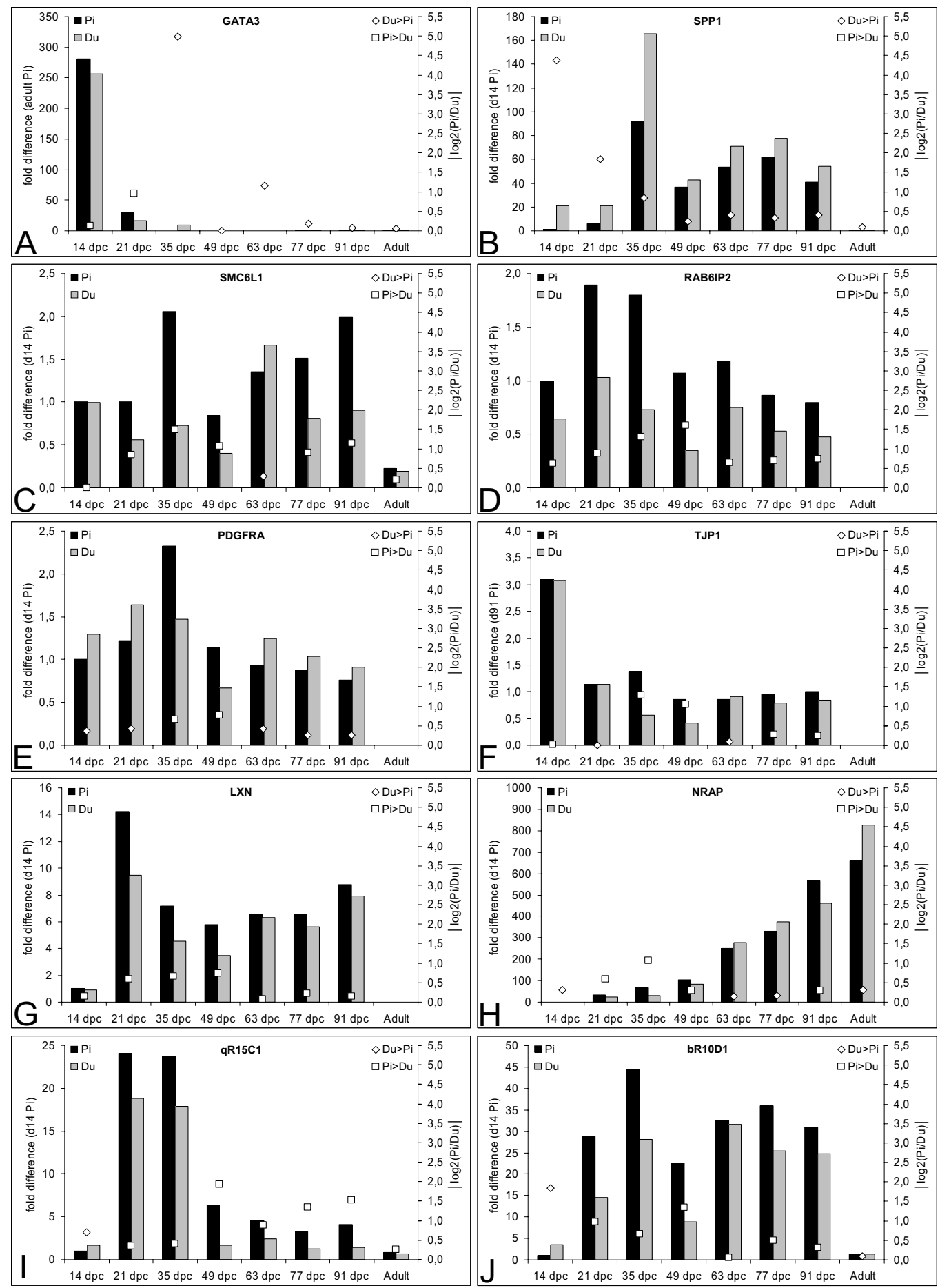

Figure 2

Expression of ten genes showing breed-associated differences in differential display RT-PCR patterns obtained by qPCR. Histograms show normalized relative gene expression in Pietrain and Duroc embryos/Musculus longissimus dorsi at seven prenatal stages and in the adults (primary y-axis). For some genes data on expression in adults is missing. Open boxes and diamonds show absolute values of the Pietrain vs. Duroc expression ratios at each stage (log2(Pi/Du)). Open diamonds indicate higher expression in Duroc compared to Pietrain individuals and open boxes indicate the reverse situation (secondary y-axis). 
The expression profile of the EST qR15C1 obtained using qPCR resembled those of the HMGA2 gene (Figure 2I). A peak was observed at 21-35 dpc and from day $49 \mathrm{dpc}$ onward the expression was maintained at low level; in Pietrain about 2-4-fold higher compared to Duroc. In adult muscle the expression was essentially switched off. The temporal expression profile of the EST qR15C1 indicated that the transcript might be involved in early development. Unfortunately, the sequence of qR15C1 was very short and showed no similarity with transcripts of known genes. We took advantage of the ongoing sequencing of the porcine genome and retrieved a trace sequence [NCBI Trace Archiv:Ti 784825315] overlapping the EST. Using this trace we were able to map the EST qR15C1 to intron 4 of the human kinesin family member 26B (KIF26B) gene (Hsa1q44, 82\% identity over 93 bp at 243749890 bp). Thus qR15C1 may represent a so far undetected exon of KIF26B.

Sequencing of the two comigrating cDNA fragments bR10D1 and qR10D1 revealed that they represent the same transcript differing only in a $3 \mathrm{bp}$ insertion/deletion and that the differences between breeds obtained using differential display RT-PCR were based on different frequencies of the insertion/deletion in Duroc and Pietrain. Nevertheless qPCR revealed that besides allelic variation the transcript represented by the EST bR10D1/qR10D1 differed also in its abundance between the two breeds (Figure 2J). In the early Duroc embryos at $14 \mathrm{dpc}$ the expression was about 4-fold higher compared to Pietrain and the situation was reversed during the first wave of myogenesis at 21-49 dpc, when the expression was about 1.5 to 2.5 -fold higher in Pietrain embryos/fetuses. The expression profile was very similar to that of SPP1, i.e. it peaked at $35 \mathrm{dpc}$ and $77 \mathrm{dpc}$ respectively.

Taken together, qPCR confirmed the differential display RT-PCR derived expression patterns for all three genes showing stage-associated differential expression and three out of ten genes with breed-associated differential expression (overall incidence of false positives $\sim 50 \%$ ). Furthermore, five of the seven breed-associated genes, whose differential display expression pattern could not be reflected in detail by qPCR, showed more than twofold differences in expression between breeds on at least one stage.

\section{Discussion \\ Identification of genes/networks expressed during skeletal muscle development in pigs}

Myogenesis in mammals is a multistep process that involves commitment of pluripotent mesodermal cells in somites to the myogenic lineage, followed by proliferation/migration of myoblasts and two waves of myoblast fusion resulting in the formation of two morphologically/ functionally distinct types of myotubes.

In the present study we performed expression profiling of skeletal muscle development in the pig using embryonic and fetal musculus longissimus dorsi tissue at seven stages covering the whole myogenesis from somitogenesis to maturation of the myotubes into myofibers. Recently Te Pas et al $[11,13]$ reported results of a similar study analyzing the same breeds and developmental stages using an application specific microarray focused on genes related to myogenic regulatory factors, energy metabolism and structural genes. Here we provide complementary data generated using differential display RT-PCR as a hypothesis free, open system. We identified 85 transcripts expressed at one or more of these key stages, evidencing their potential involvement in myogenesis. These transcripts represented 52 genes from various functional classes and 33 anonymous EST. Several of them were either not yet cloned in the pig ( $30 \%)$, or are completely novel $(\sim 20 \%)$. The identified genes and networks and their relationship with myogenesis are discussed below.

At early developmental stages (14 and $21 \mathrm{dpc}$ ) it was not feasible to dissect structures giving rise to muscle and so expression profiles of some of the transcripts may have been influenced by the heterogeneous and changing cellular composition. For $\sim 50 \%$ of the transcripts the expression profiles derived by differential display RT-PCR and qPCR are not fully compatible. In the case of stage-associated EST/genes the consistency of expression patterns in both breeds provides biological replication and thus underscores the reproducibility of the results. On the other hand, the differences in differential display RT-PCR and qPCR profiles of breed-associated EST/genes, especially of those displayed in binary fashion, may have resulted from different sensitivity of the two methods (e.g. for bR22B1/PDGFRA gene) and polymorphisms in some of the EST (e.g. bR10D1 and qR10D1). Because for qPCR very short amplicons are usually designed to achieve high amplification efficiency it is also possible that in some cases the differential display cDNA fragment and the qPCR amplicon represented different splice forms of the same gene and thus show different profiles.

The differential display patterns revealed on average some 5 bands representing either genes with stage- and/or breed-specific expression that were further assigned to groups according to their temporal expression pattern and to categories of biological functions. A subset of genes representing these categories was analysed further by qPCR. These are discussed in the following paragraphs. 


\section{Genes involved in the regulation of transcription}

Members of the myogenic regulatory factor (MRF) and myocyte enhancer factor 2 (MEF2) families of transcription factors play a central role in the regulation of myogenic determination and differentiation; however, their expression during porcine myogenesis changes only marginally [13]. Recently Blais et al [21] identified an extensive network of genes regulating transcription and chromatin architecture that propagate and amplify the myogenic signal initiated by the MRFs in vitro. Among the genes we identified, those regulating transcription represented one of the most abundantly detected functional classes, underscoring the important role of transcriptional regulation in the control of myogenesis. For the majority of genes identified, their precise role in this process is largely unknown, but because they were expressed in various 'period' groups they probably have diverse functions. The architectural transcription factor HMGA2, for example, was recently shown to promote myogenic differentiation in vitro [22]. However, the EST bS3D7 does not show homology to known cDNA sequence of HMGA2 but to a sequence segment in the intron 3 of the human HMGA2 [GenBank:AY387666], that was shown to be transcribed in uterine leiomas. Thus, EST bS3D7 probably represents a novel exon of porcine HMGA2. Several studies in humans point to the existence of alternative exons in intron 3 of HMGA2 with a complex splicing pattern [23]. The porcine EST harbours sequence features that support the hypothesis of an alternative exon - an open reading frame (ORF) with a stop codon, a polyadenylation signal and a poly-A tail. Expression of this exon would generate a HMGA2 protein with a truncated C-terminal region and lacking the acidic tail. Intriguingly, overexpression of a carboxyl-terminally truncated HMGA2 form in embryonic stem (ES) cells resulted in enhanced myogenic differentiation compared to wild type HMGA2 cells [22]. Thus the putative novel exon of porcine HMGA2 may play a specific function in myogenesis.

Another gene of this functional class, RAB6IP2, showed consistent upregulation at all seven stages in Pietrain compared to Duroc samples. The function of RAB6IP2 is poorly understood. Recently, Sigala et al [24] proposed RAB6IP2 as a part of the IkappaB kinase complex, involved in activation of the transcription factor NF-kappaB. NF-kappaB in turn inhibits myogenic differentiation and stimulates proliferation of myoblasts by activation of cyclin D1 transcription and suppression of MYOD [25]. Hence upregulation of RAB6IP2 may be an indicator for delayed myogenic differentiation via NF-kappaB in Pietrain.

\section{Genes involved in the control of cell proliferation}

Proliferation of myoblasts is stimulated by a variety of secreted peptide growth factors including insulin-like growth factors (IGFs) and platelet derived growth factors (PDGFs). These usually have reverse effect on myogenic differentiation with the exception of IGFs that stimulate both proliferation and differentiation of myoblasts [26]. We found a new and largely uncharacterized member of the IGF system, IGFBPL1, among genes expressed during the first wave of myogenesis. The IGF binding proteins (IGFBP) serve as modulators of the effects of IGFs. IGFBPL1 shows structural and functional similarity to IGFBP7 [27], that specifies the proliferative response to IGFs in myogenesis [28]. Taken together the expression pattern and similarity to IGFBP7 it implies that IGFBPL1 may also serve as a factor stimulating proliferation and/or inhibiting differentiation of embryonic myoblasts.

The expression profile of PDGFRA showed distinct differences between Pietrain and Duroc at early stages of myogenesis, with Pietrain showing a more pronounced but delayed peak. PDGFRA plays a vital role in the early myogenesis as evidenced by the PDGFRA null mouse showing impaired myotome formation [29] and (nearly) complete absence of muscles of the back [30].

\section{Cell adhesion and extracellular matrix genes}

Signals generated by adhesive interactions between myoblasts and between myoblasts and the extracellular matrix represent another essential part of the molecular network governing myogenic differentiation besides secreted factors and transcription factors [31,32]. Furthermore, cell adhesion and extracellular matrix molecules serve a structural role in myoblast fusion and migration, and provide physical support for the developing myofibers. Consistently, genes involved in cell adhesion, cell-cell signaling, and extracellular matrix synthesis and remodeling were abundantly represented and were enriched in the period 4 group, i.e. they were expressed from 21-35 dpc onward. Several of these, like IGSF1, were not yet associated with myogenesis. IGSF1 encodes a member of the immunoglobulin superfamily (IgSF) of cell surface proteins mediating cell adhesion and recognition. Diverse IgSF members have been implicated in cell-contact-based regulation of myogenesis [31]. The increasing expression of IGSF1 towards later stages suggests that it might be involved in the second wave of myogenesis.

Expression of SPP1 shows a more regulated profile with peaks at the two respective myogenic waves and consistent upregulation in Duroc compared to Pietrain, especially at the early stages. SPP1 is multifunctional matricellular protein mediating cell-adhesion and cellular signaling via integrin and CD44 receptors. Several lines of evidence indicate that SPP1 is involved in myogenesis. SPP1 is a target of MYOD and MYF5 [33] and was shown to be expressed in vitro in myoblasts and myotubes, with higher levels in the later [34]. Moreover SPP1 is downreg- 
ulated in the BC3H1 cell line, which is myogenic but do not terminally differentiate, compared to the myogenic C2C12 cell line, which differentiate normally [35]. Considering our in vivo and the in vitro evidences for an association between SPP1 expression and myogenic differentiation it appears that upregulation of SPP1 in Duroc may be a sign of accelerated myogenesis in this breed compared to Pietrain.

\section{Differential gene expression as an indicator of cellular reorganization during myogenesis}

The abundantly identified myofibrillar, cytoskeletal, and metabolism genes are indicators of the massive structural and functional remodeling occurring during the development of skeletal muscle at the cellular level, including for example formation of the contractile apparatus. Another indicator of the ongoing reorganization of cell and tissue architecture might be the expression of the autophagy genes ATG3 and UVRAG that we detected during the first and second wave of myogenesis, respectively. Autophagy is a process of bulk degradation of cytoplasmatic components that occurs in a wide range of eukaryotic organisms and in multiple different cell types during nutrient and growth factor deprivation, cellular and tissue remodeling, and cell death. The importance of autophagy for normal development is emphasized by frequent observation of dysregulation of autophagy in cancer [36]. To our best knowledge there are no reports describing autophagy and its exact role during myogenesis.

\section{Novel transcripts}

Of the 85 EST generated, 33 ( $39 \%$ ) showed no appreciable similarity to transcripts of known genes. Remarkably, these EST were enriched among the breed-associated cDNA-fragments. This finding may indicate that these EST represent alternative exons with specific temporo-spatial expression, whose alternative usage may generate transcript diversity and ultimately phenotypic (i.e. breed) diversity [37]. The expression profiles of several of these EST suggest involvement of the corresponding genes in myogenesis or prenatal development in general. One interesting example is the EST qR15C1, whose expression is upregulated at 21 and $35 \mathrm{dpc}$. The EST qR15C1 probably represents a novel exon of KIF26B since comparative genome analysis showed similarity to intron 4 of the human ortholog. Moreover, KIF26B showed a similar expression profile as it is preferentially expressed in limb buds and, most notably, in the precursors of hypaxial muscles in somites of mouse embryos [38].

\section{Implications for the understanding of the genetic control of muscle growth}

Genetic and epigenetic factors controlling proliferation, differentiation and cell death affect the number of myoblasts available for myofiber formation and thus are impor- tant determinants of muscle growth. We identified several novel genes that may be involved in these processes, e.g. IGFBPL1, during myogenesis. Particularly interesting are those genes that show differential expression between the two breeds differing in muscularity. Taken together, the breed-associated differences in the expression of RAB6IP2, PDGFRA and SPP1 suggest that myogenesis is delayed especially during the first wave in Pietrain, the more muscular of the two breeds, allowing the generation of a larger pool of muscle precursor cells. This finding is in accordance with results of Te Pas et al [11], who found that myogenesis genes show lower expression in Pietrain compared to Duroc at early stages, probably delaying formation of primary myotubes. The number and size of primary myotubes are intrinsic factors affecting secondary fiber number. In contrast to secondary myotubes, whose number is sensitive to exogenous factors, e.g. nutrition, the number of primary myotubes is genetically programmed [39]. Thus genetic selection may impinge on the first wave of myogenesis, promoting genes active at this stage as primary candidates for manipulation of muscle growth.

\section{Conclusion}

The present study revealed several genes differentially expressed during skeletal muscle development of domestic pig that were not yet associated with myogenesis and thus provide novel insights into molecular pathways employed in mammalian myogenesis (e.g. the autophagy pathway) and a foundation for future functional studies. Genes that exhibited differences between the divergent breeds represent candidate genes for muscle growth and structure. Indeed several of the identified genes map to known porcine QTL regions affecting muscle growth and/ or structure and their DNA variation is associated with variation in traits related to muscle deposition $[40,41]$.

\section{Methods}

\section{Tissue sampling and RNA extraction}

To obtain embryos/fetuses 99 Pietrain and 105 Duroc sows respectively ( 12 to 17 sows per stage) were artificially inseminated with semen from purebred sires and slaughtered at 14, 21, 35, 49, 63, 77 and 91 days post conception (dpc). Immediately after exsanguination of the sows the uteri were recovered and the embryos/fetuses were quickly removed, weighted (35 dpc onward), and dissected. Samples were frozen in liquid nitrogen and stored at $-80^{\circ} \mathrm{C}$. To harvest the embryos at $14 \mathrm{dpc}$ each uterus horn was flushed with PBS, i.e. at this stage each sample represented the whole litter of a sow. At $21 \mathrm{dpc}$ whole embryos were collected and for RNA isolation the dorsolateral part was used. At $35 \mathrm{dpc}$ precursor tissue of the back muscles was dissected from the area along the spine. From day $49 \mathrm{dpc}$ onward Musculus longissimus dorsi (Mld) tissue samples were dissected. In total about 1000 samples from each of 
the two breeds were collected. In addition Mld samples from each three Pietrain and Duroc sows respectively were obtained. All handling of the animals was done in accordance with German law for the Protection of Animals and was approved by the animal welfare protection commission of the University of Bonn and the responsible veterinary authority.

Before 49 dpc the sexual characteristics were not visible therefore gender of the embryos and fetuses at 21 and 35 dpc was determined using a PCR-based method according to [42] with minor modifications. Briefly, a fragment of the sex-determining region $\mathrm{Y}$ located on the $\mathrm{Y}$ chromosome was amplified using the primers SRYB-3 and SRYB5 along with the autosomal locus STS-Bo1 [43] serving as an internal control. The cycling parameters used were as follows: $95^{\circ} \mathrm{C}$ for $3 \mathrm{~min} ; 36$ cycles of $95^{\circ} \mathrm{C}$ for $10 \mathrm{~s}, 62^{\circ} \mathrm{C}$ for $30 \mathrm{~s}, 72^{\circ} \mathrm{C}$ for $30 \mathrm{~s}$; and $72^{\circ} \mathrm{C}$ for $5 \mathrm{~min}$.

Total RNA was isolated using TRI Reagent (Sigma, Taufkirchen, Germany) according to the manufacturer's protocol. After DNaseI treatment (Promega, Mannheim, Germany) the RNA was cleaned up using the RNeasy Kit (Qiagen, Hilden, Germany), the quantity was spectrophotometrically determined and the integrity checked by electrophoresis of 500 ng RNA on ethidium bromide stained $1 \%$ denaturing agarose gels. In addition absence of DNA contamination was checked using the RNA as a template in a PCR amplifying a fragment of the glyceraldehyde-3phosphate dehydrogenase (GAPDH) gene.

\section{Differential display $R T-P C R$}

To minimize the negative impact of individual variation in the gene expression on the expression profiles RNA pools were used for each stage and breed, i.e. 14 RNA pools were made ( 2 breeds $\times 7$ stages). With the exception of the embryo samples at $14 \mathrm{dpc}$ the pools were prepared by mixing of equal amounts of RNA from 10 individuals per breed, one male and one female sibling from 5 litters per stage. The individuals were selected according to their age and weight/size to be representative for their breeds at the chosen developmental stages. For the embryos at 14 $\mathrm{dpc}$ the individuals were already pooled during the harvesting, therefore the RNA pools were set up from uterus flushes of 5 sows per breed.

First-strand cDNA was synthesized using SuperScriptII MMLV reverse transcriptase (Invitrogen, Karlsruhe, Germany) and each of the oligo (dT) ${ }_{11} \mathrm{CG},(\mathrm{dT})_{11} \mathrm{GC}$, (dT) ${ }_{11}$ GG und (dT) ${ }_{11}$ CC primers. Differential display RTPCR was performed according to [19] using random decamer primers developed by Bauer et al. [44]. In total 88 primer combinations were used to generate differential display profiles. Each differential display RT-PCR was performed in duplicate to minimize false positives and the
PCR products from both reactions were loaded in parallel on $5 \%$ denaturing polyacrylamide gels, separated by electrophoresis for 4.5 hours and visualized by silver staining.

\section{Isolation, sequencing and annotation of the differentially displayed cDNA fragments}

Selected cDNA fragments with breed or stage-associated appearance were excised using sterile needles, eluted in 2 $\times$ PCR buffer at $4{ }^{\circ} \mathrm{C}$ overnight, precipitated using linear acrylamide as carrier, eluted in $20 \mu \mathrm{l}$ of PCR grade $\mathrm{H}_{2} \mathrm{O}$, and reamplified using the same PCR conditions as for differential display RT-PCR but with the cycle number increased to 50. Presence of the target fragment was checked by running an aliquot of the reamplification on 5 $\%$ denaturing PAA gels. The reamplified products were subsequently purified on $1 \%$ agarose gels and cloned using either the pGEM-T (Promega) or the pCR2.1 (Invitrogen) vector. Following an insert amplification using M13 primers at least two clones per fragment were sequenced on Licor 4200 sequencer using the SequiTherm EXCEL Kit (Biozym, Hess. Oldendorf, Germany) and Sp6 and T7 primers. The identity of the expressed sequence tags (EST) was first determined by BLASTN search against the nonredundant and EST GenBank repositories (BLASTN identities $>80 \%$ ). For EST for which sequence identity was found only to anonymous EST or genomic clones the corresponding gene was attempted to be identified by cross-species megaBLAST search against the human genome by taking advantage of the high homology between pig and human genome sequences. The EST for which the gene identity could be derived were assigned to functional categories based on GO annotation where available or inferred from the available literature.

\section{Real-time quantitative PCR}

Real-time quantitative PCR (qPCR) was employed for validation of the expression patterns of selected EST.

Primers and amplicons shown in Table 3, were designed using the Primer Express v2.0 (Applied Biosystems, Weiterstadt, Germany). For all target EST/genes with the exception of the SPP1 gene, the LXN gene and the EST qR15C1 the primers were designed from sequences obtained in the present study. The sequences of the EST qR14A1\#1 (LXN) and qR15C1 were too short to design primers suitable for qPCR therefore overlapping sequences, identified by BLASTN search of available porcine sequences, were used for primer/amplicon design (Table 3). For the SPP1 gene the porcine reference sequence was used (Table 3 ). Sequences of the ACTB, CANX, AGPAT1 and RPL32 genes were retrieved from GenBank by BLASTN search using the corresponding human gene as reference. The primers used for quantification of the POLR2A gene were kindly provided by Dr. Manfred Mielenz, Institute of Physiology, Biochemistry and Animal Hygiene, University of Bonn. 
Table 3: Information on primers used for $\mathrm{QPCR}$

\begin{tabular}{|c|c|c|c|c|}
\hline Gene/EST & Source & Primer Sequence & $\mathrm{Ta}\left({ }^{\circ} \mathrm{C}\right)$ & Amplicon size (bp) \\
\hline \multirow[t]{2}{*}{$A C T B^{\prime}$} & A]312193 & GAGAAGCTCTGCTACGTCGC & 59 & 231 \\
\hline & & CCTGATGTCCACGTCGCACT & & \\
\hline \multirow[t]{2}{*}{ POLR2A' } & DT324622 & GAAGGGGGAGAGACAAACTG & 60 & 86 \\
\hline & & GGGAGGAAGAAGAAAAAGGG & & \\
\hline \multirow{2}{*}{ RPL32' } & NM 001001636 & AGCCCAAGATCGTCAAAAAG & 55 & 165 \\
\hline & & TGTTGCTCCCATAACCAATG & & \\
\hline \multirow[t]{2}{*}{ AGPATII } & AL773562 & AGGACGCAACGTCGAGAACA & 60 & 110 \\
\hline & & GTGAGGGAGGGAAGTGGTGAG & & \\
\hline \multirow[t]{2}{*}{ CANXI } & A) 653783 & CAATGATGGATGGGGTCTGAA & 60 & 135 \\
\hline & & AACACAGGTAATGCCACAGTCAA & & \\
\hline \multirow[t]{2}{*}{ NMEI ${ }^{2}$} & $\underline{\mathrm{EH} 792596}$ & TGTGGAGAGCGCAGAGAAAGA & 58 & 143 \\
\hline & & GGGAGAGAGGAGAAATGGAATGG & & \\
\hline \multirow[t]{2}{*}{$\mid G S F I^{2}$} & EH792632 & GAGTCCACCCCATCTACTGTTCC & 60 & 60 \\
\hline & & AAATCCССTTGACCCATCTCA & & \\
\hline \multirow[t]{2}{*}{ HMGA2 2} & EH79260I & AAGGAGGCAGAAGCAGAATGA & 59 & 74 \\
\hline & & TGGAGACCCTCAGAGACAAGAA & & \\
\hline \multirow[t]{2}{*}{ GATA3 $^{3}$} & $\underline{\mathrm{EH}} 792592$ & CTTAGGGAAGATGAGTCTGAATGG & 59 & 125 \\
\hline & & TTTTGAAGGCAGAAAGCGAAG & & \\
\hline \multirow[t]{2}{*}{$S P P I^{3}$} & $\underline{X 16575}$ & TTGCTAAAGCCTGACCCATCT & 60 & 145 \\
\hline & & CGTCGTCCACATCGTCTGTT & & \\
\hline \multirow[t]{2}{*}{$S M C 6 L I^{3}$} & EH792668 & TGAGGCAGTATCAAGAAGCAAAAG & 58 & 189 \\
\hline & & AACAACAGCAACAAAAGAGCCAA & & \\
\hline \multirow[t]{2}{*}{$R A B 6 I P 2^{3}$} & $\underline{\mathrm{EH}} 792612$ & GGATGTGAAGGAGCGGAAAG & 60 & 121 \\
\hline & & AGCCTGCAATGATTTGACTCG & & \\
\hline \multirow[t]{2}{*}{ PDGFRA ${ }^{3}$} & $\underline{E H 792663}$ & CAGGCAGGTTGGAGGGAGAT & 60 & 101 \\
\hline & & AAGTTGCGGAGGTTGGATTCT & & \\
\hline \multirow[t]{2}{*}{$T J P I^{3}$} & EH792652 & CTGGGCTCTTGGCTTGCTATTC & 60 & 130 \\
\hline & & СTCCTCCTGCCGTTTTTGG & & \\
\hline \multirow[t]{2}{*}{$L X N^{3}$} & CB477731 & CAAGCAAGTGCAAAGAAATGATG & 60 & 151 \\
\hline & & TGGCAGACGGCTGTTATGTT & & \\
\hline \multirow[t]{2}{*}{ NRAP3 } & $\underline{E H 792618}$ & AAGTGAGGCAGTCTCCAGAGG & 60 & 86 \\
\hline & & CATATCCCAGTGAAACACCGAT & & \\
\hline \multirow{2}{*}{$q R / 5 \mathrm{Cl}^{3}$} & $\underline{\text { Ti784825315 }}$ & ACAGTGAGAGCGAGCGTGATG & 60 & 158 \\
\hline & & TGCTTTCCCTTTATCGGAGG & & \\
\hline \multirow[t]{2}{*}{$b R I O D I^{3}$} & DQ631863 & GCTACACATTCAGCACAGAGTAAGA & 60 & 126 \\
\hline & & CTGGGGAAAGACTCCAAAAGA & & \\
\hline
\end{tabular}

\footnotetext{
'Reference gene

${ }^{2}$ Gene showing stage-associated differential expression as revealed by differential display RT-PCR

${ }^{3}$ Gene showing breed-associated differential expression as revealed by differential display RT-PCR
}

Template first strand cDNA for validation was synthesized from the original 14 RNA pools used for the differential display RT-PCR using SuperScriptIII MMLV reverse transcriptase (Invitrogen) in a reaction containing $1 \mu \mathrm{g}$ RNA and oligo $(\mathrm{dT})_{11} \mathrm{VN}$ primer according to the manufacturer's protocol. In addition cDNA was synthesized using RNA pools from Mld tissue of 3 adult sows per breed as template.

Absolute quantification of the expression was performed on an ABI Prism 7000 SDS Instrument SDS v1.1 using the SYBR Green JumpStart Taq ReadyMix (Sigma) or, for the GATA3 and the RPL32 genes, on a LightCycler 1.0 System using the LightCycler FastStart DNA Master SYBRplus Green I (Roche Diagnostics, Mannheim, Germany). All reactions were performed in duplicate with standard devi- ation between replicates kept below fifty percent. On the ABI Prism 7000 SDS Instrument a two-step PCR was performed with an initial denaturation at $95^{\circ} \mathrm{C}$ for $10 \mathrm{~min}$ and 45 cycles of $95^{\circ} \mathrm{C}$ for $15 \mathrm{~s}$ for denaturation and oneminute annealing/extension at optimized temperature (Ta, Table 3). The fluorescence was acquisited at the end of each cycle at a fixed temperature of $60^{\circ} \mathrm{C}$. On the LightCycler instrument the qPCR consisted of an initial denaturation step at $95^{\circ} \mathrm{C}$ for $10 \mathrm{~min}$ and 45 cycles consisting of $95^{\circ} \mathrm{C}$ for $10 \mathrm{~s}$, optimal Ta for $15 \mathrm{~s}$ and extension at $72^{\circ} \mathrm{C}$ for $15 \mathrm{~s}$. The fluorescence was acquisited at the end of the extension step. After completion of the qPCR on both instruments melting curve analysis and afterwards agarose gel electrophoresis were performed to confirm specificity of the amplification. 
For all assays threshold cycles were converted to copy numbers using a standard curve generated by amplifying serial dilutions of an external plasmid standard $\left(10^{7}-10^{1}\right.$ copies). To account for variation in RNA input and efficiency of reverse transcription the calculated copy numbers were normalized by dividing with a normalization factor derived from the expression of the five (three for adult stage) reference genes. First, for each reference gene a correction factor was calculated within stage and breed by dividing the quantity obtained for the corresponding breed by the mean quantity of the two breeds at that specific stage. The normalizing factor was then calculated for each breed and stage based on the geometric mean of the five (three) correction factors.

\section{Competing interests}

The author(s) declares that there are no competing interests.

\section{Authors' contributions}

EM participated in sampling, carried out differential display RT-PCR analysis and data analysis and wrote the manuscript. MM carried out sequencing, sequence annotation and qPCR analysis. SP provided input to design of the study, participated in sampling and assisted drafting the manuscript and revising it critically for scientific content. KS made contribution to the study design. KW significantly contributed to the concept, design and coordination of the study and in drafting the manuscript. All authors read and approved the final manuscript.

\section{Acknowledgements}

The pregnant sows were provided by Institute for Pig Genetics B.V., Beuningen, The Netherlands and Züchtungszentrale Deutsches Hybridschwein Gmbh, Lueneburg, Germany. The Duroc samples were collected by Drs M. Te Pas and B. Harlizius. This work was supported by funds provided by the EU Project PorDictor (QLK-2000-0I363) (coordinator K. Wimmers).

\section{References}

I. Perry RLS, Rudnicki MA: Molecular mechanisms regulating myogenic determination and differentiation. Front Biosci 2000 , 5:D750-D767.

2. Parker MH, Seale P, Rudnicki MA: Looking back to the embryo: Defining transcriptional networks in adult myogenesis. Nat Rev Genet 2003, 4:497-507.

3. Rehfeldt C, Fiedler I, Dietl G, Ender K: Myogenesis and postnatal skeletal muscle cell growth as influenced by selection. Livest Prod Sci 2000, 66: 177-188.

4. Wimmers K, Ngu NT, Jennen DGJ, Tesfaye D, Murani E, Schellander $\mathrm{K}$, Ponsuksili S: Muscle size-associated transcript abundance of myosin heavy chain isoforms in longissimus dorsi muscle in different pig breeds. J Anim Sci 2007 in press.

5. Ashmore CR, Addis PB, Doerr L: Development of Muscle Fibers in Fetal Pig. J Anim Sci 1973, 36:1088-1093.

6. Swatland HJ, Cassens RG: Prenatal Development, Histochemistry and Innervation of Porcine Muscle. I Anim Sci 1973, 36:343-354.

7. Stickland NC, Handel SE: The Numbers and Types of MuscleFibers in Large and Small Breeds of Pigs. J Anat 1986, 147:181-189.

8. Lefaucheur L: Myofibre typing and its relationships to growth performance and meat quality. Arch Tierzucht 2006, 49:4-17.
9. Zhao S, Nettleton D, Liu W, Fitzsimmons C, Ernst C, Raney N, Tuggle $\mathrm{C}$ : Complementary DNA macroarray analyses of differential gene expression in porcine fetal and postnatal muscle. J Anim Sci 2003, 8 I:2 I 79-2I 88.

10. Sudre K, Leroux C, Pietu G, Cassar-Malek I, Petit E, Listrat A, Auffray C, Picard B, Martin P, Hocquette JF: Transcriptome analysis of two bovine muscles during ontogenesis. J Biochem 2003, 133:745-756.

II. Cagnazzo M, Te Pas MFW, Priem J, De Wit AAC, Pool MH, Davoli R, Russo V: Comparison of prenatal muscle tissue expression profiles of two pig breeds differing in muscle characteristics. J Anim Sci 2006, 84: I- I0.

12. Cassar-Malek I, Passelaigue F, Bernard C, Leger J, Hocquette JF: Target genes of myostatin loss-of-function in muscles of late bovine fetuses. BMC Genomics 2007, I (8):63.

13. Pas M, Pool M, Hulsegge I, Janss L: Analysis of the differential transcriptome expression profiles during prenatal muscle tissue development in pigs. Arch Tierzucht 2006, 49: I I0-I I5.

14. Kuhn G, Fiedler I, Ender K, Matthes W: Duroc and Pietrain breedings in comparison. Fleischwirtschaft 2005, 85:92-96.

15. Radonic A, Thulke S, Mackay IM, Landt O, Siegert W, Nitsche A: Guideline to reference gene selection for quantitative realtime PCR. Biochem Biophys Res Commun 2004, 3 I 3:856-862

16. Zhao SH, Recknor J, Lunney JK, Nettleton D, Kuhar D, Orley S, Tuggle CK: Validation of a first-generation long-oligonucleotide microarray for transcriptional profiling in the pig. Genomics 2005, 86:618-625.

17. Hsiao LL, Dangond F, Yoshida T, Hong R, Jensen RV, Misra J, Dillon W, Lee KF, Clark KE, Haverty P, Weng ZP, Mutter GL, Frosch MP, MacDonald ME, Milford EL, Crum CP, Bueno R, Pratt RE, Mahadevappa M, Warrington JA, Stephanopoulos G, Stephanopoulos G, Gullans SR: A compendium of gene expression in normal human tissues. Physiol Genomics 200I, 7:97-104.

18. Warrington JA, Nair A, Mahadevappa M, Tsyganskaya M: Comparison of human adult and fetal expression and identification of 535 housekeeping/maintenance genes. Physiol Genomics 2000, 2:143-I47.

19. Ponsuksili S, Wimmers K, Schellander K: Application of differential display RT-PCR to identify porcine liver ESTs. Gene 200I, 280:75-85.

20. Niemann CU, Krag TOB, Khurana TS: Identification of genes that are differentially expressed in extraocular and limb muscle. J Neurol Sci 2000, 179:76-84

21. Blais A, Tsikitis M, costa-Alvear D, Sharan R, Kluger Y, Dynlacht BD: An initial blueprint for myogenic differentiation. Genes Dev 2005, 19(5):553-569.

22. Caron L, Bost F, Prot M, Hofman P, Binetruy B: A new role for the oncogenic high-mobility group A2 transcription factor in myogenesis of embryonic stem cells. Oncogene 2005, 24:6281-6291.

23. Hauke S, Leopold S, Schlueter C, Flohr AM, Escobar HM, Rogalla P, Bullerdiek J: Extensive expression studies revealed a complex alternative splicing pattern of the HMGA2 gene. Biochim Biophys Acta 2005, I729(I):24-3I

24. Sigala JLD, Bottero V, Young DB, Shevchenko A, Mercurio F, Verma IM: Activation of transcription factor NF-kappa B requires ELKS, an I kappa B kinase regulatory subunit. Science 2004, 304:1963-1967.

25. Guttridge DC, Mayo MW, Madrid LV, Wang CY, Baldwin AS: NFkappa B-induced loss of MyoD messenger RNA: Possible role in muscle decay and cachexia. Science 2000, 289:2363-2366.

26. Florini JR, Ewton DZ, Coolican SA: Growth hormone and the insulin-like growth factor system in myogenesis. Endocr Rev 1996, 17:48I-5I7.

27. Cai Z, Chen HT, Boyle B, Rupp F, Funk WD, Dedera DA: Identification of a novel insulin-like growth factor binding protein gene homologue with tumor suppressor like properties. Biochem Biophys Res Commun 2005, 33 I:26I-266.

28. Haugk KL, Wilson HMP, Swisshelm K, Quinn LS: Insulin-like growth factor (IGF)-binding protein-related protein-I: An autocrine/paracrine factor that inhibits skeletal myoblast differentiation but permits proliferation in response to IGF. Endocrinology 2000, 141:100-110.

29. Soriano P: The PDGF alpha receptor is required for neural crest cell development and for normal patterning of the somites. Development 1997, 124:2691-2700. 
30. Schatteman GC, Morrison-Graham K, van KA, Weston JA, BowenPope DF: Regulation and role of PDGF receptor alpha-subunit expression during embryogenesis. Development 1992, II5:|23-13|.

31. Krauss RS, Cole F, Gaio U, Takaesu G, Zhang W, Kang JS: Close encounters: regulation of vertebrate skeletal myogenesis by cell-cell contact. J Cell Sci 2005, I I 8:2355-2362.

32. Osses N, Brandan E: ECM is required for skeletal muscle differentiation independently of muscle regulatory factor expression. Am J Physiol Cell Physiol 2002, 282:C383-C394.

33. Ishibashi J, Perry RL, Asakura A, Rudnicki MA: MyoD induces myogenic differentiation through cooperation of its $\mathrm{NH2}$ - and COOH-terminal regions. J Cell Biol 2005, I 7 I:47 I-482.

34. Pereira RO, Carvalho SN, Stumbo AC, Rodrigues CAB, Porto LC, Moura AS, Carvalho L: Osteopontin expression in coculture of differentiating rat fetal skeletal fibroblasts and myoblasts. In Vitro Cell Dev Biol Anim 2006, 42:4-7.

35. Sharp SB, Villalvazo M, Huang M, Gonzalez R, Alarcon I, Bahamonde M, D'Agostin DM, Damle S, Espinosa A, Han SJ, Liu J, Navarro P, Salguero $\mathrm{H}$, Son J, Vu S: Further characterization of BC3H I myogenic cells reveals lack of p53 activity and underexpression of several p53 regulated and extracellular matrix-associated gene products. In Vitro Cell Dev Biol Anim 2002, 38:382-393.

36. Levine B, Klionsky DJ: Development by self-digestion: Molecular mechanisms and biological functions of autophagy. Dev Cell 2004, 6:463-477.

37. Hughes TA: Regulation of gene expression by alternative untranslated regions. Trends Genet 2006, 22:1 19-122.

38. Marikawa Y, Fujita TC, Alarcon VB: An enhancer-trap LacZ transgene reveals a distinct expression pattern of Kinesin family 26B in mouse embryos. Dev Genes Evol 2004, 2 I 4:64-7I.

39. Maltin CA, Delday MI, Sinclair KD, Steven J, Sneddon AA: Impact of manipulations of myogenesis in utero on the performance of adult skeletal muscle. Reproduction 200I, I 22:359-374.

40. Wimmers K, Murani E, Te Pas MFW, Chang KC, Davoli R, Merks JWM, Henne H, Muraniova M, Da Costa N, Harlizius B, Schellander K, Böll I, Braglia S, De Wit AAC, Cagnazzo M, Fontanesi L, Prins D, Ponsuksili S: Associations of functional candidate genes derived from gene expression profiles of prenatal porcine muscle tissue with meat quality and muscle deposition. Anim Genet 2007, 38(5):474-484.

4I. Liu G, Jennen DG, Tholen E, Juengst $H$, Kleinwachter T, Holker M, Tesfaye D, Un G, Schreinemachers HJ, Murani E, Ponsuksili S, Kim JJ, Schellander K, Wimmers K: A genome scan reveals QTL for growth, fatness, leanness and meat quality in a Duroc-Pietrain resource population. Anim Genet 2007, 38:24I-252.

42. Pomp D, Good BA, Geisert RD, Corbin CJ, Conley AJ: Sex Identification in Mammals with Polymerase Chain-Reaction and Its Use to Examine Sex Effects on Diameter of Day-10 Or Day-I I Pig Embryos. J Anim Sci 1995, 73:|408-14I5.

43. Wimmers K, Murani E, Ponsuksili S, Yerle M, Schellander K: Detection of quantitative trait loci for carcass traits in the pig by using AFLP. Mamm Genome 2002, 13:206-210.

44. Bauer D, Muller H, Reich J, Riedel H, Ahrenkiel V, Warthoe P, Strauss M: Identification of Differentially Expressed Messenger-Rna Species by An Improved Display Technique (Ddrt-Pcr). Nucleic Acids Res 1993, 21:4272-4280.

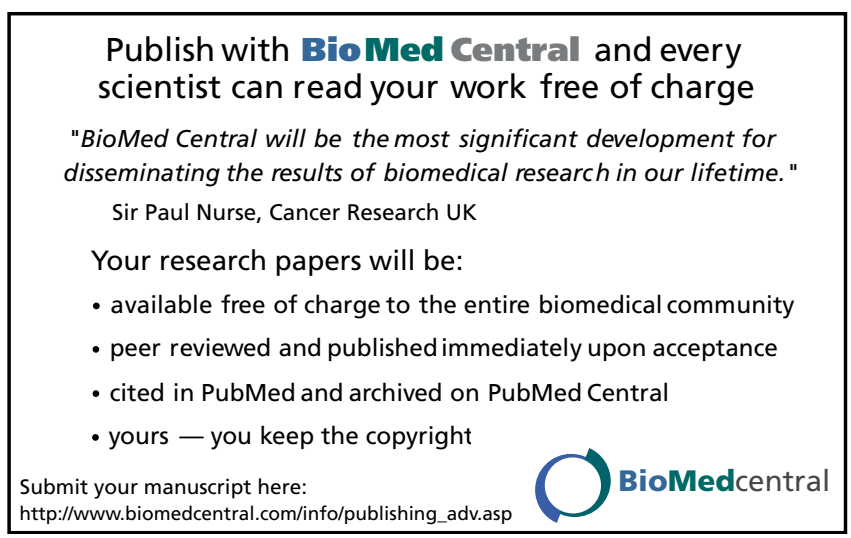

